OSWALD SPENGLER Moctezuma. Un drama (1897)

Edición y estudio introductorio de Anke Birkenmaier

Traducción de Manuel Cuesta 



\section{Oswald Spengler}

\section{Moctezuma. Un drama (1897)}

Edición y estudio introductorio

ANKe BirkenMaier

Traducción

Manuel Cuesta

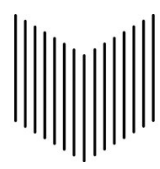

Iberoamericana - Vervuert - 2020 

Cualquier forma de reproducción, distribución, comunicación pública o transformación de esta obra solo puede ser realizada con la autorización de sus titulares, salvo excepción prevista por la ley. Diríjase a CEDRO (Centro Español de Derechos Reprográficos) si necesita fotocopiar o escanear algún fragmento de esta obra (www.conlicencia.com; 91702 $1970 / 932720447)$

Esta edición es una traducción actualizada de:

Anke Birkenmaier: Versionen Montezumas.

(C) Walter de Gruyter GmbH Berlin Boston. All rights reserved.

This work may not be translated or copied in whole or part without the written permission of the publisher (Walter De Gruyter GmbH, Genthiner Straße 13, 10785 Berlin).

(C) Iberoamericana, 2020

Amor de Dios, 1 - E-28014 Madrid

Tel.: +34914293522

info@iberoamericanalibros.com

www.iberoamericana-vervuert.es

(C) Vervuert, 2020

Elisabethenstr. 3-9 - D-60594 Frankfurt am Main

Tel.: +49695974617

ISBN 978-84-9192-079-3 (Iberoamericana)

ISBN 978-3-96456-867-0 (Vervuert)

ISBN 978-3-96869-109-1 (ebook)

Depósito legal: M-16702-2020

Ilustración de la cubierta: Frontispicio de Th. Armin, Das alte Mexiko oder die Eroberung von Neuspanien, Leipzig, 1865. Fotografía de Carola Seifert. Bildarchiv Preussischer Kulturbesitz / Art Resource, NY.

Diseño de cubierta: Eva Bajo 
